\title{
Effects of urban agglomeration on surface-UV doses: a comparison of Brewer measurements in Warsaw and Belsk, Poland, for the period 2013-2015
}

\author{
Agnieszka E. Czerwińska, Janusz W. Krzyścin, Janusz Jarosławski, and Michał Posyniak \\ Institute of Geophysics, Polish Academy of Sciences, 01452 Warsaw, Poland \\ Correspondence to: Agnieszka E. Czerwińska (aczerwinska@igf.edu.pl)
}

Received: 29 April 2016 - Published in Atmos. Chem. Phys. Discuss.: 28 June 2016

Revised: 13 October 2016 - Accepted: 17 October 2016 - Published: 3 November 2016

\begin{abstract}
Specific aerosols and cloud properties over large urban regions seem to generate an island, similar to the wellknown urban heat island, leading to lower ultraviolet (UV) radiation intensity compared to the surrounding less polluted areas, thus creating a shield against excessive human exposure to UV radiation. The present study focuses on differences between erythemal and UVA $(324 \mathrm{~nm})$ doses measured by the Brewer spectrophotometers in Warsaw $\left(52.3^{\circ} \mathrm{N}\right.$, $\left.21.0^{\circ} \mathrm{E}\right)$ and Belsk $\left(51.8^{\circ} \mathrm{N}, 20.8^{\circ} \mathrm{E}\right)$. The latter is a rural region located about $60 \mathrm{~km}$ south-west of the city. Ratios between erythemal and UVA partly daily doses, obtained during all-sky and cloudless-sky conditions for the period May 2013-December 2015, were analysed to infer a specific cloud and aerosol forcing on the surface UV doses over Warsaw. Radiative model simulations were carried out to find sources of the observed differences between the sites. It was found that Warsaw urban agglomeration induced 8 and $6 \%$ attenuation of the erythemal and UVA doses respectively. This is mostly due to the lower sun elevation in Warsaw during the near-noon measurements and the larger optical depth of the city aerosols and increased cloudiness. It could be hypothesised that the expected stronger absorption of the solar UV radiation by urban aerosols is compensated for here by a higher surface reflectivity over the city.
\end{abstract}

\section{Introduction}

Excessive exposure to the ultraviolet radiation (UVR) reaching the Earth's surface has a detrimental impact on human health. The overexposure to UVB radiation $(290-315 \mathrm{~nm})$ can cause erythema (redness of the skin), DNA and cellular damage (due to the generation of reactive oxygen species), and immunosuppression. Longer UV wavelengths, UVA (315-400 nm), can be cancerogenic but can also be responsible for photoageing and various eye diseases, including cataracts. Overexposure to both UVB and UVA could lead to increased risks of cutaneous melanoma, non-melanoma skin cancers, and various other health problems (e.g. Marionnet et al., 2014; Greinert et al., 2015). While UVB is strongly dependent on the latitude and thickness of the ozone layer, UVA, especially UVA1, the so-called long-wave UVA (340$400 \mathrm{~nm}$ ), is ozone independent, more intense, and less variable with latitude (Sabziparvar et al., 1999). In the spectral range up to $\sim 330 \mathrm{~nm}$, absorption by ozone is usually much stronger than absorption by other main trace gases $\left(\mathrm{SO}_{2}\right.$, $\mathrm{NO}_{2}$ ) (Cede et al., 2006).

The intensity of the solar UV radiation at the Earth's surface depends significantly on properties and amount of clouds and aerosols. Upward UVB and UVA trends have been reported over several mid-latitudinal sites of the Northern Hemisphere since the beginning of the 1990s, which have been mainly attributed to decreasing attenuation by aerosols and clouds (e.g. Krzyścin et al., 2011; Zerefos et al., 2012; De Bock et al., 2014).

Attenuation of the incoming solar radiation seems to be higher over large urban agglomerations relative to surrounding rural areas due to the excessive light scattering and absorption by anthropogenic aerosols. Papayannis et al. (1998) found differences between cloudless-sky UV irradiances measured over Athens and a suburban area near Athens. In Athens, the concentration of atmospheric aerosols was higher than at the suburban site. The erythemal irradiance at the 
centre of Athens was up to $30 \%$ lower than at the suburban site during days with increased air pollution over the Athens basin. A similar difference was noticed in the modelled UVB irradiance with input from measurements of the total ozone $\left(\mathrm{TO}_{3}\right)$ and aerosols optical depth (AOD) by the Brewer spectrophotometer (BS) at the outskirts of Athens. Acosta and Evans (2000) measured erythemal irradiances in the centre and suburbs of Mexico City in the period 1994-1995. During this period in winter, the erythemal irradiance was $9 \%$ greater in the suburbs than in the centre of Mexico City, while during summer, the recorded values were up to $43 \%$ greater (the mean value was $21 \%$ ). Corr et al. (2009) found strong absorption of UVR by urban aerosols over Mexico City with a single scattering albedo (SSA) in the range $0.7-0.85$. Even larger attenuation $(\sim 60 \%)$ of the UVR due to aerosols was reported in Guangzhou, China, in the dry season from October to January in years 2000, 2004, and 2006 (Deng et al., 2012). Kazadzis et al. (2009a) found that for some cloudless days, differences in AOD among three sites (urban, rural, and industrial) located in Thessaloniki and at the outskirts of the city can account for up to $20 \%$ differences in the UV irradiance. Fountoulakis et al. (2016) noticed that positive trends in the amount of absorbing urban aerosols over Thessaloniki might counteract the expected UVR increase due to the longterm decrease of AOD there.

The atmosphere over Poland is one of the most particulate matter (PM) polluted in Europe. $\mathrm{PM}_{10}$ and $\mathrm{PM}_{2.5}$ levels measured in Warsaw, as well as in most other larger cities in Poland, exceed the tolerable PM limit many times during the year (Polish Ministry of Environment, 2014). However, Zawadzka et al. (2013) analysed measurements taken by the Microtops II and CIMEL sun photometer and stated that a small positive bias for AOD at $500 \mathrm{~nm}$ between Warsaw and a rural site (Belsk), which is $\sim 60 \mathrm{~km}$ south-west of the city, was not larger than 0.02 , whereas for lower values of wind velocity the difference reached 0.04 . The bias calculated from satellite measurements with MODIS (Moderate Resolution Imaging Spectroradiometer) was $\sim 0.05$. The authors did not find any significant differences in the Angström parameters between the sites for the visible range, so it could be hypothesised that AOD values in the UV range also differ only slightly. However, for organic particles, the absorption in the UV range may be larger than predicted using Ångström parameters for the visible range of the spectrum (Bais et al., 2015). Similar differences to those between Warsaw and Belsk were reported by Chubarova et al. (2011), who analysed results of aerosol measurements by the CIMEL sun photometers located in Moscow (megacity with a population over 10 million) and Zvenigorod (population of up to $20000)$.

It seems possible that a large urban agglomeration could generate specific cloud properties (due to the heat island effect and the creation of specific cloud condensation nuclei consisting of urban aerosols), higher loading of aerosols, and higher albedo than that in rural sites. The working hypothesis is that the Warsaw agglomeration produces a kind of shield against the incoming UV radiation.

\section{Methodology}

Monitoring of the UV spectra by BS is carried out by the Institute of Geophysics, Polish Academy of Sciences (IGF PAS), at the Central Geophysical Observatory Belsk since 1992 by the single monochromator BS, serial number 64 (BS064), and in Warsaw since 2013 by the double monochromator BS, serial number 207 (BS207) installed on the roof (elevation $\sim 25 \mathrm{~m}$ above street level) of the IGF PAS main building. Previously, BS207 was working at Belsk (20102013). Comparison of BS064 and BS207 for that period will allow us to assess the differences between the measured UV doses due to instrumental differences. BS207 was moved to Warsaw in the middle of 2013.

The present study focuses on differences in the erythemal and UVA (324 nm) doses measured by the BSs in Warsaw $\left(52.3^{\circ} \mathrm{N}, 21.0^{\circ} \mathrm{E}, 130 \mathrm{~m}\right.$ a.m.s.1.) and Belsk $\left(51.8^{\circ} \mathrm{N}\right.$, $20.8^{\circ} \mathrm{E}, 190 \mathrm{~m}$ a.m.s.1.). The wavelength $324 \mathrm{~nm}$ was chosen because it is one of the longest wavelengths measured directly by both $\mathrm{BSs}$ and because the gaseous absorption by the main trace gases $\left(\mathrm{O}_{3}, \mathrm{NO}_{2}\right.$, and $\left.\mathrm{SO}_{2}\right)$ is weak at this wavelength. The Belsk observatory is located in a rural region (the largest orchard region in Poland) far from urban and industrial developments. Surroundings of the city measuring site consist of grass, trees, concrete constructions (buildings, pedestrian footpaths), and asphalt roads.

BS064 is an older generation instrument, Mark II type, which is equipped with a single monochromator. Its spectral range is $290-325 \mathrm{~nm}$ in $0.5 \mathrm{~nm}$ steps and it has a spectral resolution of $0.6 \mathrm{~nm}$ (FWHM). The spectral accuracy decreases for higher values of AOD and for larger solar zenith angles, i.e. for cases with an enlarged contribution of the diffuse component in the total UV radiation that increases the stray-light effect on the instrument (Bais et al., 1996). Furthermore, it does not have a ventilation system. The quality control of its performance has been assessed by almost yearly calibration against the travelling world standard BS, serial number 17 (BS017). BS017 itself is regularly compared with a set of three Brewer instruments, the so-called "Brewer reference triad" (Fioletov et al., 2005). BS064 was also compared with Bentham DM-150 during the project Quality Assurance of Spectral Ultraviolet Measurements (QUASUME) in May 2004 (Gröbner et al., 2005, 2006). The estimated $1 \sigma$ uncertainty of the erythemal irradiance is about $5 \%$ (Gröbner and Schreder, 2004).

BS207 is the newest type instrument, Mark III, equipped with a double monochromator, which significantly reduces the stray-light effect. It is also equipped with a ventilation system, which prevents overheating of the instrument during hotter days. Its spectral characteristics are the same as BS064; however, the spectral range is wider and extends to 
363 nm. BS207 was calibrated against BS017 in 2012 and 2013. After the calibration in 2013, it was moved to Warsaw. Furthermore, it has been calibrated three to four times per year since 2010 with a set of standard lamps that allow elimination of instrument ageing (loss of its sensitivity to UVR). For both instruments, the SHICRivm software was used to extend the spectra up to $400 \mathrm{~nm}$ and to eliminate erroneous spectra (Slaper et al., 1995).

The erythemal irradiance is calculated as the integral over the wavelength range $290-400 \mathrm{~nm}$ BS spectra after the SHICRivm standardization, which is weighted by the erythemal action spectrum. The UVA $(324 \mathrm{~nm})$ irradiance is taken without any weighting. The erythemal action spectrum is that suggested by the Commission Internationale de l'éclairage (CIE) (CIE, 1987). Furthermore, the partly daily erythemal and UVA (324 nm) doses are calculated as a time integral of the pertaining irradiance for the $6 \mathrm{~h}$ period for all-sky conditions (local noon $-3 \mathrm{~h}$, local noon $+3 \mathrm{~h}$ ) and the $3 \mathrm{~h}$ period for cloudless-sky conditions (local noon $-3.5 \mathrm{~h}$, local noon $-0.5 \mathrm{~h}$ ). Cloudless-sky conditions are identified using a two-step algorithm. The first step is a preliminary search for such days using the criterion: the solar UV irradiance derivative with solar zenith angle is negative. In the next step, the smoothness of the time series for the day, which fulfilled the first criterion, is examined, i.e. the bell shape of the UV time series must be identified. There is no strict mathematical criterion applied here, but rather an intuitive inspection of the time series shape.

Ratios between erythemal and UVA (324 nm) doses measured by BS064 and BS207, based on collocated observations at Belsk for the period October 2010-April 2013, allow us to estimate the uncertainty range of the ratio related to differences in BS instrumental characteristics and in time of observations. The BS measurements are not synchronized, as the spectrum ranges are different. The same ratios are measured for the period of the Warsaw observations (May 2013 to December 2015) by BS207 and BS064 at Belsk to assess the impact of the urban agglomeration on the erythemal and UVA radiation. The LOWESS (locally weighted scatter plot smoothing) filter (Cleveland, 1979) was used for smoothing of the curves.

Numerical simulations for the cloudless-sky conditions of the ratio between Warsaw and Belsk were performed to calculate differences caused by various factors, such as the geographical location (Belsk is slightly to the south), $\mathrm{TO}_{3}$, surface albedo, and aerosols properties (AOD, SSA). Simulations were performed with the radiation transfer model (RTM) libRadtran (Mayer and Kylling, 2005). The following model input parameters, which are from the simultaneous measurements at both sites, are used in the following calculations: daily mean total ozone by the BSs standard measurements and AOD at $550 \mathrm{~nm}$ measured by the MODIS for the period 2013-2015. MODIS Aerosol Product values are available globally and include AOD at $550 \mathrm{~nm}$ over land and ocean. Remote sensing of aerosol properties using MODIS is presented by Ichoku et al. (2004). In this study, we used arrays of Level 2 (MOD 04, Collection 6) data produced daily at the spatial resolution of $10 \times 10 \mathrm{~km}$ pixelation. From satellite data, we selected daily mean values of AOD from the nearest pixel to the measurement sites. Other input parameters are constants representing typical values used in the UV modelling, e.g. albedo of 0.03 for rural surfaces and $\mathrm{SSA}=0.92$, which is a mean value measured by the CIMEL sun photometer at Belsk (level 1.5 from AERONET (Aerosol Robotic Network)) at $440 \mathrm{~nm}$ (http://aeronet.gsfc.nasa.gov). Since there are no AERONET-related measurements of SSA at UV wavelengths, we used SSA at $440 \mathrm{~nm}$ as a constant for the whole ultraviolet spectrum, as it was found that monthly averages estimated from BS in Uccle, Belgium, were in close agreement with the CIMEL measurements at $440 \mathrm{~nm}$, especially for $320 \mathrm{~nm}$ (Nikitidou et al., 2013). To identify the impact of the selected parameter on the ratio between the sites' doses we use the RTM model, allowing variability only for this parameter and keeping constant other RTM input parameters. For example, to quantify the dependence of the ratio on the geographical location of the sites the RTM simulations were performed using fixed $\mathrm{TO}_{3}, \mathrm{AOD}$, and time (10:40 GMT), but the simulations were for consecutive days throughout the whole year.

\section{Results}

\subsection{Comparison between measurements at Belsk}

In the period from October 2010 to April 2013 both BSs were working simultaneously at Belsk. Figure 1a shows the time series of the measured ratio (BS064/BS207) between the $6 \mathrm{~h}$ erythemal all-sky doses. The mean value of the ratio between erythemal doses is $1.02 \pm 0.07(1 \sigma)$. Figure $1 \mathrm{~b}$ illustrates that the $1: 1$ relation between the doses is appropriate for the whole range of measured irradiances. The coefficient of determination based on this data set is 0.99 . The mean ratio for UVA $(324 \mathrm{~nm})$ is $1.02 \pm 0.07(1 \sigma)$ for all-sky conditions.

Outliers greater than $10 \%$ sometimes appear, as the measurements were not synchronous. It is difficult to have synchronized measurements by our BSs, as the scanning time is different because of the various spectral ranges, i.e. 290$325 \mathrm{~nm}$ for BS064 and 290-363 nm for BS207. BS064 measures UV spectrum three times per hour, BS207 only two times per hour. Thus, local cloudiness may be a source of large standard deviations of the mean ratios calculated during all-sky conditions. To remove the effect of cloudiness, we analysed the ratios derived from $3 \mathrm{~h}$ cloudless-sky measurements before solar noon. The cloudless-sky doses were calculated for a shorter period compared to those for the allsky conditions, as cloudless-sky conditions in Poland usually prevail before noon. 

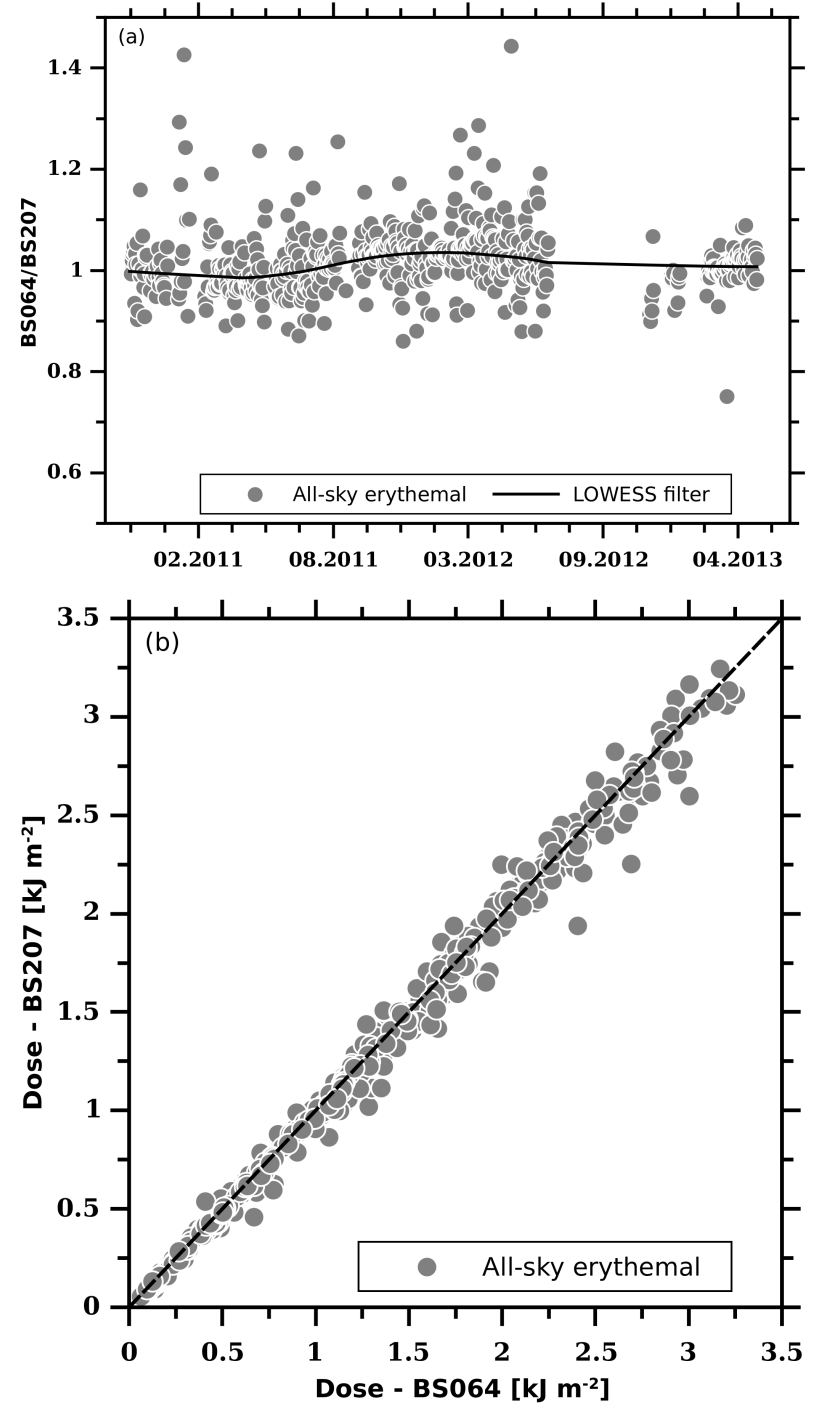

Figure 1. (a) The ratio between erythemal $6 \mathrm{~h}$ (noon $\pm 3 \mathrm{~h}$ ) doses measured by the Brewer spectrophotometers Nos. 64 and 207 while working simultaneously at Belsk (all-sky conditions). The solid curve represents the data smoothed by the LOWESS filter. (b) Scatter plot of doses measured by Brewer spectrophotometers Nos. 207 and 64 .

Figure $2 \mathrm{a}$ shows the time series of the measured BS064 / BS207 ratio for the cloudless-sky conditions and the corresponding scatter plot (Fig. 2b). The mean value of the ratio is $1.01 \pm 0.03(1 \sigma)$ and there is almost a $1: 1$ relation between the erythemal doses by both BSs. This is also supported by a high value $(0.998)$ of the coefficient of determination. For UVA $(324 \mathrm{~nm})$ doses, the ratio is $1.00 \pm 0.03(1 \sigma)$. Thus, the performance of BS064 and BS207 was practically the same during the Belsk intercomparison. The agreement between the output of both BSs was almost perfect, suggesting that the instrumental differences did not have much influence on the ratio between the doses.
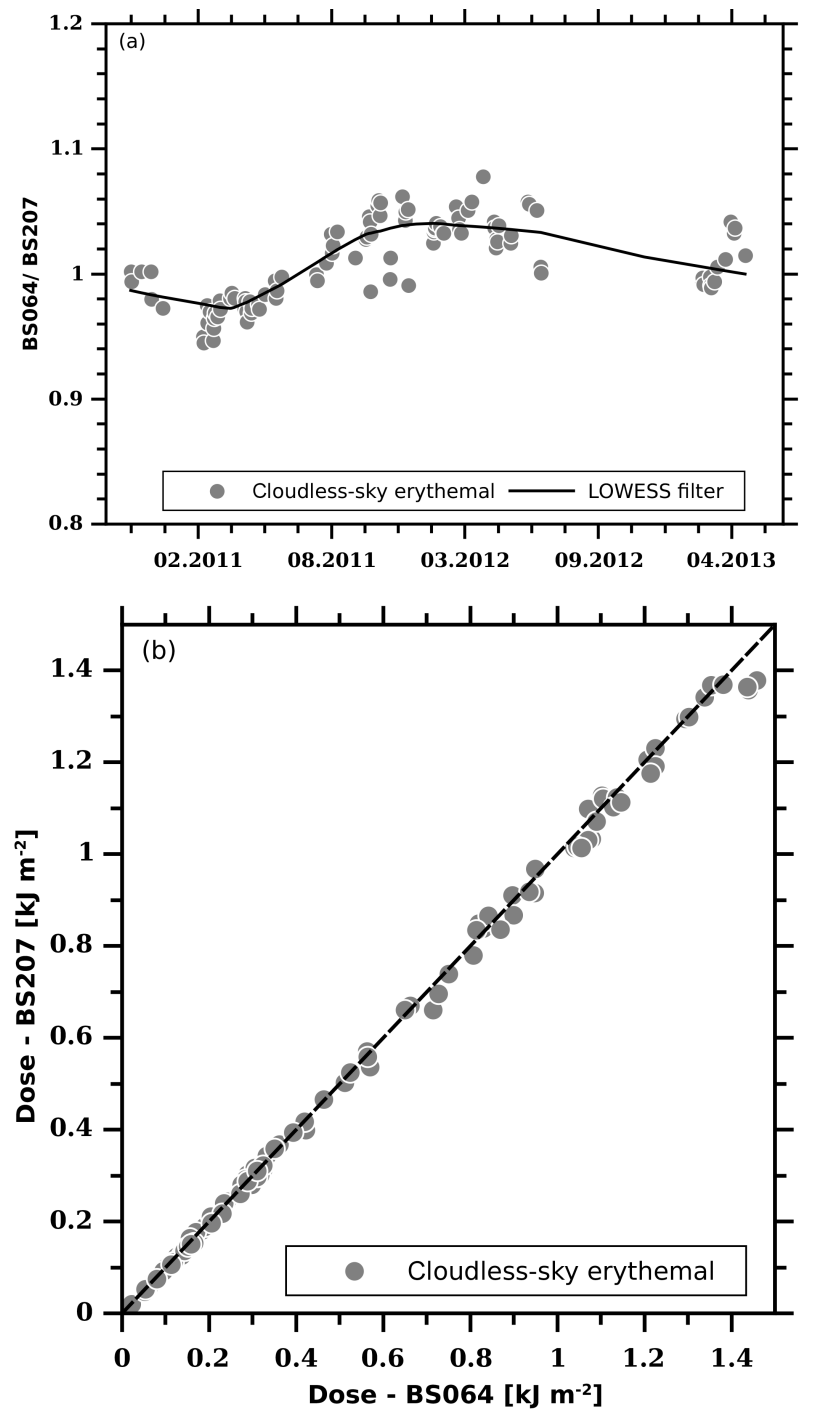

Figure 2. (a) Same as Fig. 1a but for cloudless-sky conditions and $3 \mathrm{~h}$ doses calculated for the period before noon (noon $-3.5 \mathrm{~h}$, noon $-0.5 \mathrm{~h}$ ). (b) Same as Fig. 1b but for cloudless-sky conditions and $3 \mathrm{~h}$ doses calculated for the period before noon (noon $-3.5 \mathrm{~h}$, noon $-0.5 \mathrm{~h})$.

\subsection{Comparison between measurements at Belsk and Warsaw}

BSs were working simultaneously in Warsaw and Belsk in the period from May 2013 to December 2015. The erythemal and UVA $(324 \mathrm{~nm})$ doses calculated for these sites for $6 \mathrm{~h}$ periods (local noon $-3 \mathrm{~h}$, local noon $+3 \mathrm{~h}$ ) for all-skies, and $3 \mathrm{~h}$ periods (local noon $-3.5 \mathrm{~h}$, local noon $-0.5 \mathrm{~h}$ ) for cloudless-skies, were analysed to find the Belsk / Warsaw ratio between the measured doses (BS064 / BS207). If the ratio obtained during the cloudless-sky conditions differs significantly from that obtained during the cloudless-sky conditions during the Belsk BSs intercomparison, it will allow us to es- 

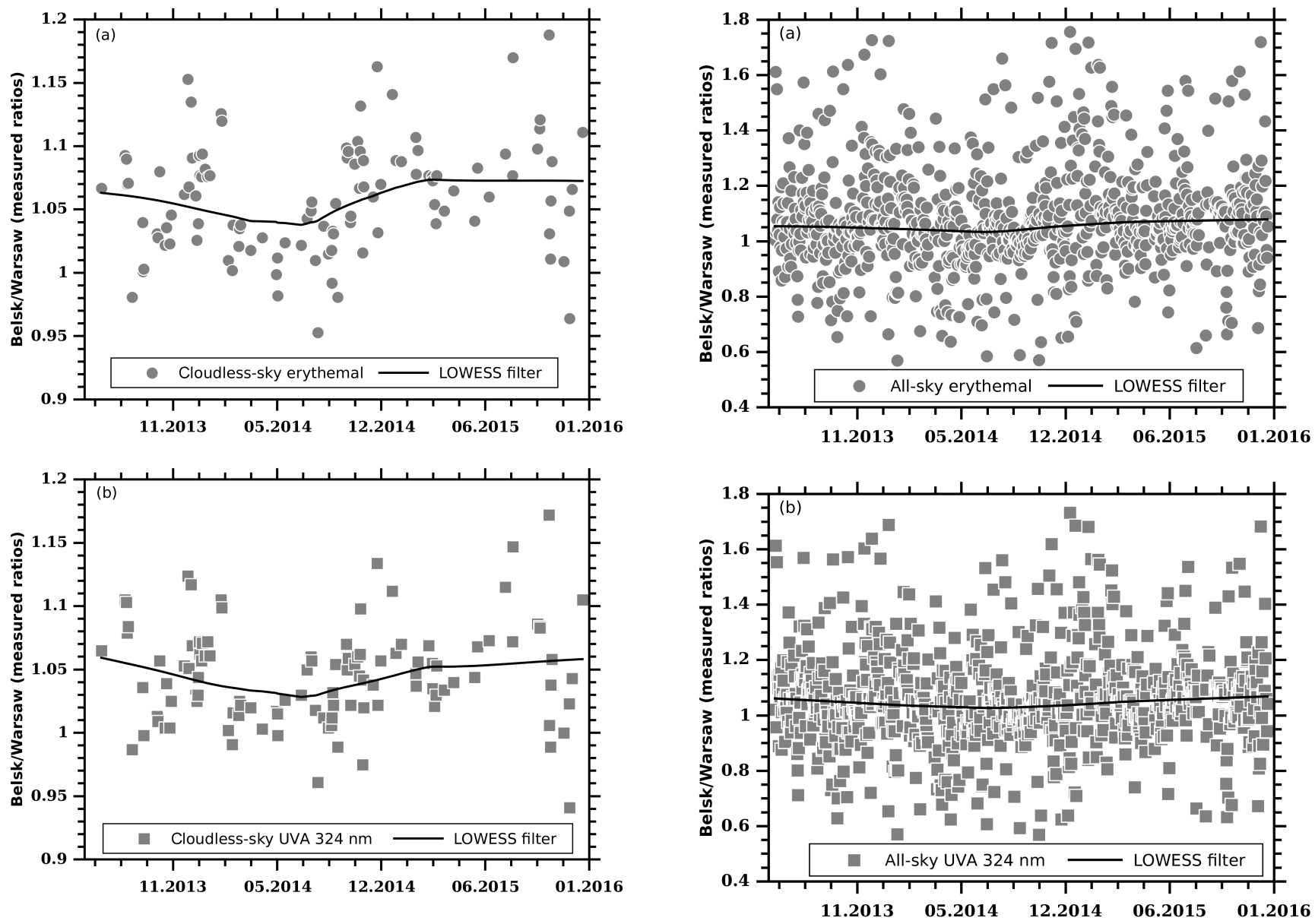

Figure 3. The Belsk / Warsaw ratio between the partial daily $3 \mathrm{~h}$ doses (noon $-3.5 \mathrm{~h}$, noon $-0.5 \mathrm{~h}$ ) measured during cloudless-sky conditions existing over both sites for erythemal doses (a) and UVA ( $324 \mathrm{~nm}$ ) doses (b). Solid curves represent the data smoothed by the LOWESS filter.

timate the effect of urban aerosols on the surface UVR. A similar approach with the use of all-sky data will also provide an estimate of the effect of urban cloud on the surface UVR.

Figure 3 shows the time series of BS064 / BS207 measured ratio for erythemal doses (Fig. 3a) and the UVA (324 nm) doses (Fig. 3b) for cloudless-sky conditions simultaneously appearing both in Warsaw and Belsk during $3 \mathrm{~h}$ measurements. The ratio oscillates around 1.05 within the range between 0.9 and 1.2. The main reason for this scatter is using the interpolated erythemal (or UVA) irradiance values at the beginning (local noon $-3.5 \mathrm{~h}$ ) and at the end (local noon $-0.5 \mathrm{~h}$ ) of the calculated period. BS observations rarely coincided with these moments. Thus, linear interpolated values were used, taken from observations closest to the beginning or to the end of the period, i.e. the irradiance values just outside the observing period were also taken into account. The mean value of the Belsk / Warsaw ratio is $1.06 \pm 0.04(1 \sigma)$ and $1.04 \pm 0.04(1 \sigma)$ for the erythemal and

Figure 4. Same as Fig. 3 but for the near-noon partial daily dose (noon $-3 \mathrm{~h}$, noon $+3 \mathrm{~h}$ ) for all-sky conditions. Solid curves represent the data smoothed by the LOWESS filter.

UVA $(324 \mathrm{~nm})$ dose respectively. The corresponding values calculated for $6 \mathrm{~h}$ doses during all-sky conditions (Fig. 4) are $1.08 \pm 0.19(1 \sigma)$ and $1.06 \pm 0.18(1 \sigma)$ respectively. Much larger uncertainty ranges of the estimates for all-sky conditions are due to the cloudiness effects, but the mean values of the ratio are only slightly larger than those found during the Belsk intercomparison of the instruments. In spite of possible different cloud properties over Belsk and Warsaw during $6 \mathrm{~h}$ measurements, the determination coefficient values are still high, i.e. equal to 0.96 for erythemal and UVA ( $324 \mathrm{~nm}$ ) doses. The $1: 1$ correspondence between doses is maintained for the whole range of the data (Fig. 5).

The standard statistical test for a difference in the mean values taken from two large samples of an unknown distribution (Daniel and Cross, 2013) was used to find out if the BS064 / BS207 mean ratio obtained during the Belsk / Warsaw comparison of BSs is significantly larger than the ratio found during the Belsk intercomparison. The hypothesis that the mean value of the BS064 / BS207 ratio is higher during the Belsk / Warsaw comparison is supported 

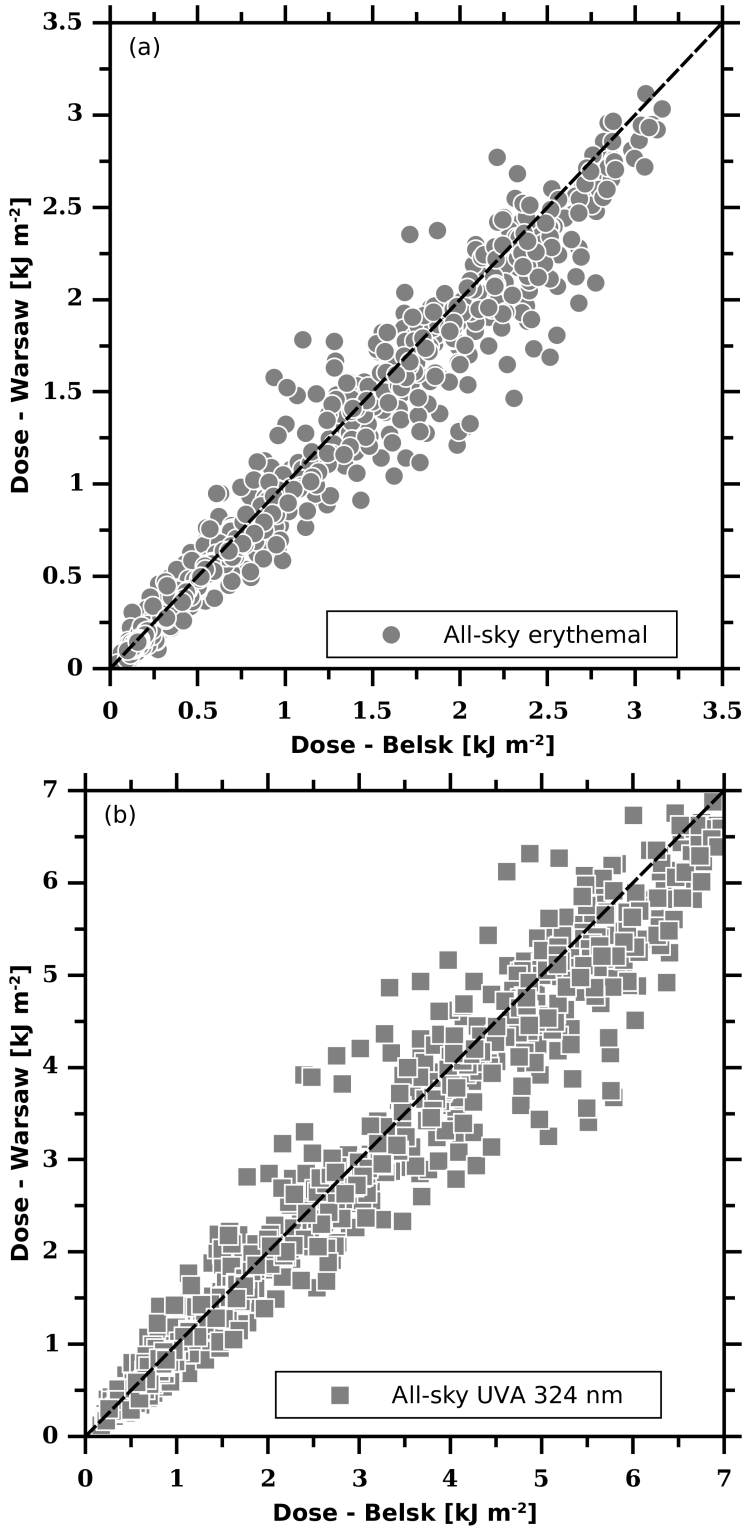

Figure 5. Scatter plot of partial daily doses (local noon $-3 \mathrm{~h}$, local noon $+3 \mathrm{~h}$ ) measured in Warsaw and Belsk: erythemal doses (a) and UVA (324 nm) doses (b).

by the test at the significance level better than 0.01 both for cloudless-sky and all-sky conditions.

\subsection{Sources of the Belsk-Warsaw differences in the erythemal and UVA doses}

The more northern location of the Warsaw site results in a lower SZA of $\sim 0.5^{\circ}$ at the same time for BSs observations. Other factors affecting the ratio between the measured doses at the rural and urban site during cloudless-sky conditions are differences in $\mathrm{TO}_{3}$, surface albedo, and aerosol properties (AOD or SSA). In this subsection, the modelled cloudless-
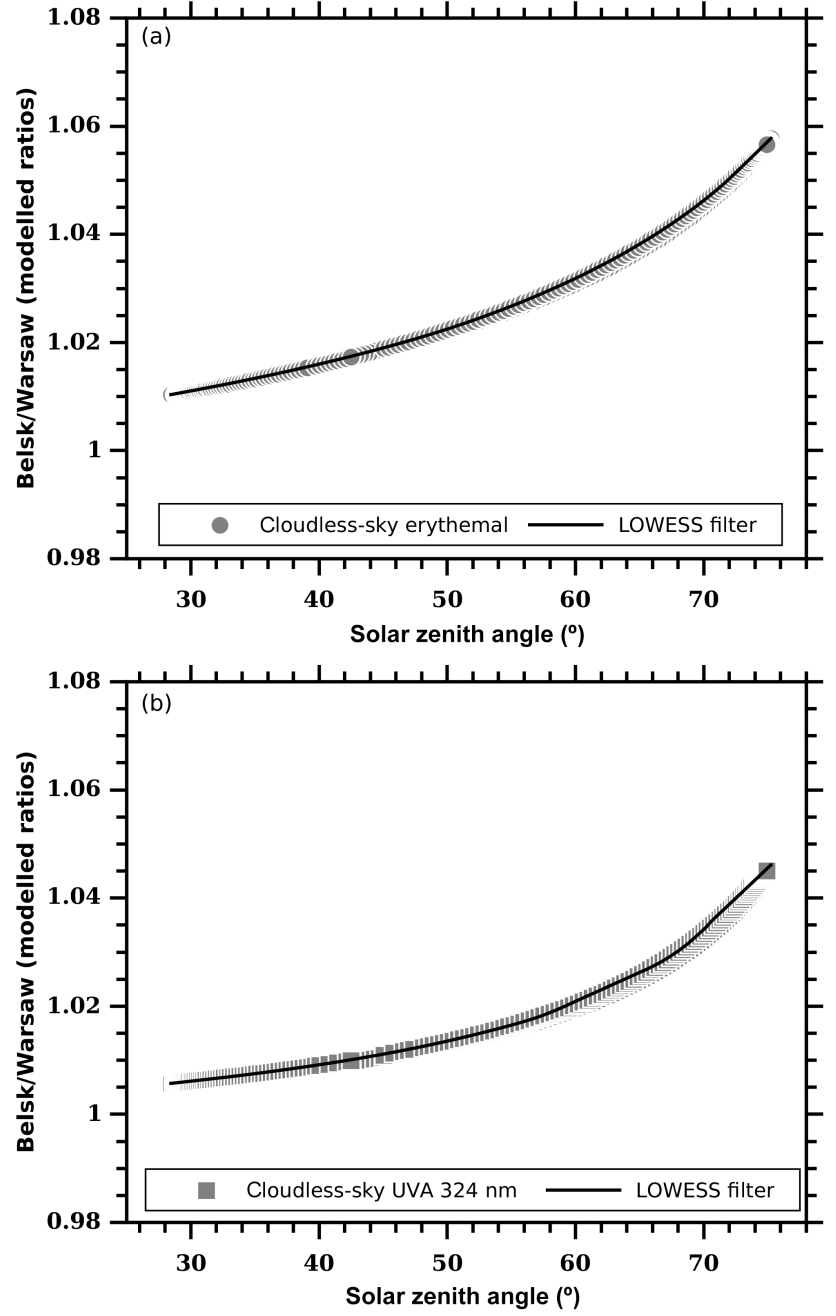

Figure 6. The Belsk / Warsaw ratio between erythemal (a) and UVA $(324 \mathrm{~nm})$ (b) irradiances calculated by the libRadtran model for 2015 vs. SZA at Belsk for the 10:40 (GMT). The solid curve represents the data smoothed by the LOWESS filter.

sky irradiances are analysed for Warsaw and Belsk to discuss sources of the BS064 / BS207 ratio variability.

The difference in the geographical coordinates for the sites, which are based on the simulations of the erythemal and UVA irradiances at 10:40 GMT (i.e. near local noon) throughout 2015, leads to slightly higher values at Belsk. The modelled ratio changes with SZA (Fig. 6). The average ratio over the whole year is $1.03 \pm 0.02(1 \sigma)$ for the erythemal irradiance and $1.02 \pm 0.01(1 \sigma)$ for UVA $(324 \mathrm{~nm})$. For the warm period (from 15 May to 14 September) modelled ratios were $1.01 \pm 0.003(1 \sigma)$ and $1.01 \pm 0.002(1 \sigma)$, but for the cold period (from 15 September to 14 May) modelled ratios were $1.04 \pm 0.01(1 \sigma)$ and $1.03 \pm 0.01(1 \sigma)-$ for erythemal and UVA $(324 \mathrm{~nm})$ irradiances respectively. To eliminate the SZA's effect on the ratios, we also calculated mean irradiance ratios for specified SZA windows for 

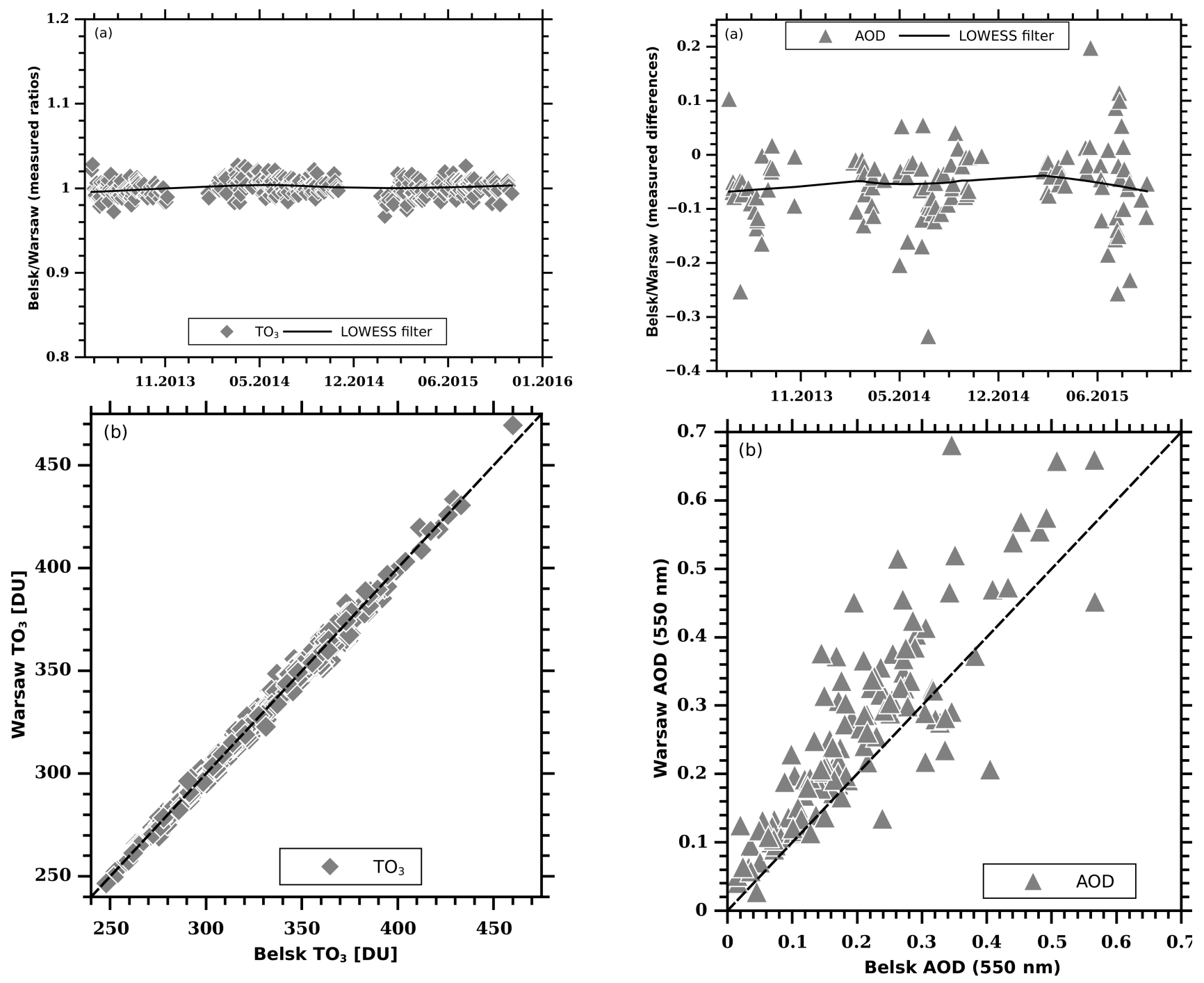

Figure 7. (a) The ratio between total ozone values measured by Brewer spectrophotometers Nos. 64 and 207 while working simultaneously at Belsk and in Warsaw for the period May 2013December 2015. The solid curve represents the data smoothed by the LOWESS filter. (b) Scatter plot of total ozone values measured by Brewer spectrophotometers Nos. 207 and 64 while working simultaneously in Belsk and Warsaw from May 2013 to December 2015 .

cloudless-sky conditions. Calculations were done for SZA windows $45 \pm 1,60 \pm 1$, and $75 \pm 1^{\circ}$. For erythemal irradiances, the ratios were $1.02 \pm 0.05(1 \sigma), 1.03 \pm 0.04(1 \sigma)$, and $1.02 \pm 0.05(1 \sigma)$ respectively. For UVA $(324 \mathrm{~nm})$ irradiances, the ratios were $1.02 \pm 0.05(1 \sigma), 1.02 \pm 0.04(1 \sigma)$, and $1.01 \pm 0.04(1 \sigma)$.

The total ozone difference between the sites is quite small (Fig. 7). The mean $\mathrm{TO}_{3}$ ratio (BS064 / BS207) taken from all coinciding daily $\mathrm{TO}_{3}$ values is $1.00 \pm 0.01(1 \sigma)$. All data points are in close proximity to the diagonal line representing the 1:1 relationship between the variables (Fig. 7b).

Figure 8. (a) The difference between AOD at $550 \mathrm{~nm}$ measured simultaneously by MODIS over Belsk and Warsaw in the period May 2013-December 2015. The solid curve represents the data smoothed by the LOWESS filter. (b) Scatter plot of AOD at $550 \mathrm{~nm}$ measured by MODIS over Belsk and Warsaw from May 2013 to December 2015.

The mean-modelled ratios between the erythemal and UVA $(324 \mathrm{~nm})$ irradiances calculated for the selected fixed SZA and the site-measured $\mathrm{TO}_{3}$ values are $1.00 \pm 0.01(1 \sigma)$ and $1.00 \pm 0.002(1 \sigma)$ respectively for all considered SZAs (30, 40,50 , and $60^{\circ}$ ). Thus, $\mathrm{TO}_{3}$ is not a factor responsible for the UV difference between the sites.

The AOD effect on the Brewers' ratio is inferred from the RTM simulations based on the measured AOD at $550 \mathrm{~nm}$ by MODIS for the period 2013-2015 on days when the data were available for both sites. Daily AOD means are taken into consideration. The calculation was performed separately for various SZAs $\left(40,60\right.$, and $\left.70^{\circ}\right)$ and fixed SSA $=0.92$. Figure 8 shows that AOD at $550 \mathrm{~nm}$ is slightly higher over 
the city. The mean AOD is equal to 0.26 and 0.20 over the urban and rural sites respectively. RTM simulations performed using the observed AOD values for various fixed SZAs (40, 60 , and $70^{\circ}$ ) yield a Belsk / Warsaw ratio that is almost the same $1.02 \pm 0.02(1 \sigma)$ for all considered SZAs and for the erythemal and UVA $(324 \mathrm{~nm})$ irradiances. All calculated ratios are shown in Table 1.

\section{Discussion and conclusions}

Warsaw agglomeration has a population of over 3.5 million, with high pollution due to heavy vehicle emissions and industry (mainly electric power), causing numerous cases over the EU air quality threshold (Monitoring System of Air Quality in Mazowieckie Region, http://sojp.wios.warszawa.pl/). Like other large cities, it is expected that Warsaw produces the well-known heat island that makes specific boundary layer, i.e. in the boundary layer factors like wind, temperature, moisture, turbulence, and energy budget fields, differ from nearby rural sites (e.g. Fortuniak et al., 2006; Miao et al., 2009; Haberlie et al., 2015), allowing anthropogenic aerosols to reach higher atmospheric layers that may enhance AOD and affect cloud properties (e.g. level of cloudiness, droplet size, liquid water content).

The Warsaw agglomeration only slightly attenuates the erythemal and UVA $(324 \mathrm{~nm})$ radiation. Under cloudless conditions, the Belsk / Warsaw ratio between the erythemal and UVA $(324 \mathrm{~nm}$ ) doses is $\sim 1.06$ and $\sim 1.04$, whereas the ratio is $\sim 1.08$ and $\sim 1.06$ for all-sky conditions respectively. The aerosol effects are responsible for $\sim 2 \%$ larger erythemal and UVA near-noon doses at Belsk, which stays in agreement with calculations of irradiance ratios between the sites for specified SZA windows $\left(45 \pm 1,60 \pm 1\right.$, and $\left.75 \pm 1^{\circ}\right)$. After eliminating the SZA's effect for cloudless-sky conditions, both erythemal and UVA $(324 \mathrm{~nm})$ irradiances at Belsk were $\sim 2 \%$ higher than in Warsaw. The cloud effects add $2 \%$, enlarging the Belsk / Warsaw ratio. The SZA effects due to the longitudinal/latitudinal difference between the sites lead to $3 \%$ (or $2 \%$ ) greater erythemal (or UVA) doses at Belsk. The difference is even larger in the cold period of the year (for higher SZAs). The unexplained 1\%-higher doses at the rural site for the erythemal doses ratio could be attributable to instrument issues.

It seems possible that urban aerosols lead to higher absorption of the UV irradiance, i.e. small SSA values $(<0.9)$ could characterize such aerosols. On the other hand, the albedo of urban surfaces is higher in the snowless period, which may compensate for the effects of lower urban aerosol SSA. Analysing the UV radiation in the Mexico City metropoli$\tan$ area, Castro et al. (2001) found the urban albedo of 0.12 over asphalt and grey surface cement sites. This is 4 times larger than the commonly used albedo of 0.03 over grass. Parisi et al. (2003) found that over some non-shaded parts of the city with high albedo (e.g. concrete surface) there is
Table 1. Mean ratios and corresponding standard deviations for comparison between UV doses and irradiances (erythemal, UVA - $324 \mathrm{~nm}$ ) modelled (mod.) by libRadtran and measured (meas.) by BSs in Warsaw (W) and Belsk (B) for cloudless-sky conditions. B / B is a ratio between doses for BSs intercomparison (BS064 / BS207) at Belsk.

\begin{tabular}{lrr}
\hline & $\begin{array}{r}\text { Ratio } \\
\text { (erythemal) }\end{array}$ & $\begin{array}{r}\text { Ratio } \\
(324 \mathrm{~nm})\end{array}$ \\
\hline $\mathrm{B} / \mathrm{W}, \mathrm{SZA} 45^{\circ} \pm 1^{\circ}$ (meas.) & $1.02 \pm 0.05$ & $1.02 \pm 0.05$ \\
$\mathrm{~B} / \mathrm{W}, \mathrm{SZA} 60^{\circ} \pm 1^{\circ}$ (meas.) & $1.03 \pm 0.04$ & $1.02 \pm 0.04$ \\
$\mathrm{~B} / \mathrm{W}, \mathrm{SZA} 75^{\circ} \pm 1^{\circ}$ (meas.) & $1.02 \pm 0.05$ & $1.01 \pm 0.04$ \\
$\mathrm{~B} / \mathrm{B}$ (meas.) & $1.01 \pm 0.03$ & $1.00 \pm 0.03$ \\
$\mathrm{~B} / \mathrm{W} \mathrm{SZA} \mathrm{(mod.)}$ & $1.03 \pm 0.02$ & $1.02 \pm 0.01$ \\
$\mathrm{~B} / \mathrm{W}$ TO (mod.) & $1.00 \pm 0.01$ & $1.00 \pm 0.00$ \\
$\mathrm{~B} / \mathrm{W}$ AOD (mod.) & $1.02 \pm 0.02$ & $1.02 \pm 0.02$ \\
$\mathrm{~B} / \mathrm{W}$ (meas.) & $1.06 \pm 0.04$ & $1.04 \pm 0.04$ \\
\hline
\end{tabular}

an amplification of human exposure of up to $7 \%$ for people in the upright position. We performed RTM simulations to show that the effect of higher surface albedo in Warsaw (the UV irradiances increase) can be compensated for by lower values of SSA. We did not measure surface albedo and SSA values. Thus, we assume that the surface albedo can be in the range of 0.03-0.12 in Warsaw and 0.03 at Belsk. If we also assume that SSA at Belsk is 0.92, which is a mean value measured by CIMEL photometer at $440 \mathrm{~nm}$, using RTM we calculate an SSA down to 0.86 and 0.85 , (for SZA $=60$ and $30^{\circ}$ respectively) for the maximum albedo difference. Such a hypothesis could only be backed up with additional aerosol absorption measurements at the two sites.

Fountoulakis et al. (2016) discussed factors important for the UV spectral variability in Thessaloniki. They pointed out that the cloudless-sky UVA irradiances could be sensitive not only to AOD changes but also to SSA changes. Kazadzis et al. (2009b) found that UVA irradiance increase in Thessaloniki for the period 1998-2006 cannot be explained only by the AOD changes, but also by the changes of SSA over the area, due to the improvement of the air quality there. Chubarova et al. (2011) analysing results by CIMEL sun photometers located in Moscow and in Zvenigorod (less polluted site) found that the uncertainty range of SSA is too high, precluding discussion of the SSA urban effects. However, they found that SSA in Moscow for the visible range of solar radiation was $0.02-0.03$ smaller than that obtained from the clean site. It is worth mentioning that there is a lack of direct retrieval to obtain SSA from UV spectral measurements. An indirect method for BS was proposed by Bais et al. (2005) depending on the assumed values of the asymmetry parameter, surface albedo, aerosol vertical profile, and the extraterrestrial solar spectrum.

The cloud effects should be more pronounced during the warm period of the year, where the urban heat island may generate stronger convection than that in the cold period of 
the year. Romanov (1999) analysing NOAA satellite images retrieved higher cloud cover in summer over central Moscow compared to its suburbs. Inoue and Kimura (2004) found that there were more low-level clouds in the summer period (July-August) in Tokyo compared to rural sites in Kantō region. Moreover, urban heat islands lead to more thunderstorm initiation episodes (e.g. Shepherd, 2005; Haberlie et al., 2015).

The classical theory (Twomey, 1977) states that when there are more aerosols high above the surface due to a stronger updraft generated by the urban heat island, aerosols serve as cloud condensation nuclei and reduce the size of cloud effective radius and increase the number of droplets, causing larger cloud optical thickness (COT) and higher attenuation of radiation reaching the Earth's surface. Thus, additional cloudiness generated over large cities may act as an umbrella against excessive UV radiation. We calculate BS064 / BS207 ratio during the Belsk / Warsaw comparison campaign taking into account measurements in the warm period, 15 May-14 September. We expected to find a higher ratio for that period according to the classical theory stated above. However, the ratio is slightly lower, i.e. $1.06 \pm 0.17$ $(1 \sigma)$, for the erythemal doses, and $1.06 \pm 0.16(1 \sigma)$ for UVA $(324 \mathrm{~nm})$ doses, and part of this difference is the effect of different SZAs between the sites. This may suggest that contrary to expectation, COT is smaller over urban areas. Jin et al. (2005) discussed the aerosol-cloud relationship over New York and Houston. They found that thick urban aerosols correspond to low COT there. Thus, it seems possible that increased cloudiness over urban areas does not necessarily mean increased attenuation of solar radiation since modification of the cloud structure and properties by the urban aerosols may lead to the formation of clouds, which attenuate the solar radiation less effectively.

Our study proves that the UV level in Warsaw is slightly lower than that found in cleaner suburbs of the city. The differences that were attributed to AOD differences are in the order of the accuracy of the instruments used. In Warsaw the dominant wind direction was from the west, south-west (allsky conditions) and east, south-east (clear-sky) in the period 2013-2015, so Warsaw did not have an impact on AOD at Belsk. Furthermore, Pietruczuk (2013) found that the advection of air masses to Belsk is mostly from the westerly direction. However, despite the fact that Warsaw is one of the most air-polluted cities in Poland, AOD in Warsaw could be lowered by existing city ventilation paths (City of Warsaw, 2006). Most of these paths seem to generate micro-advection from nearby forests and parks. Based on the Brewer measurements, urban aerosols and clouds over Warsaw only partially act as an effective shield against excessive UVR.

\section{Data availability}

The data from Brewer spectrophotometers is available upon request. To obtain the data, please contact J. Jarosławski (januszj@igf.edu.pl). The data from AERONET is available freely online at http://aeronet.gsfc.nasa.gov/ (NASA, 2016a). The data from MODIS is available freely online at https: //ladsweb.nascom.nasa.gov/search/ (NASA, 2016b).

Acknowledgements. This work was partially supported by statutory activities No. 3841/E-41/S/2016 of the Ministry of Science and Higher Education of Poland. We appreciate the support from early-career-scientist grant (A. Czerwińska) No. 500-10-18 by the Institute of Geophysics, Polish Academy of Sciences. The publication has been (partially) financed by the Leading National Research Centre (KNOW) received by the Centre for Polar Studies for the period 2014-2018. We also acknowledge the MODIS mission scientists and associated NASA personnel for the production of the data used in this research effort.

Edited by: S. Kazadzis

Reviewed by: U. Feister and one anonymous referee

\section{References}

Acosta, L. R. and Evans, F. J.: The design of the Mexico City UV monitoring network: UV-B measurements at ground level in the urban environment, J. Geophys. Res., 105, 5017-5026, 2000.

Bais, A. F., Zerefos, C. S., and McElroy, C. T.: Solar UVB measurements with the double- and single-monochromator Brewer ozone spectrophotometers, Geophys. Res. Lett., 238, 833-836, doi:10.1029/96GL00842, 1996.

Bais, A. F., Kazantzidis, A., Kazadzis, S., Balis, D. S., Zerefos, C. S., and Meleti, C.: Deriving an effective aerosol single scattering albedo from spectral surface UV irradiance, Atmos. Environ., 39, 1093-1102, 2005.

Bais, A. F., McKenzie, R. L., Bernhard, G., Aucamp, P. J., Ilyas, M., Madronich, S., and Tourpali, K.: Ozone depletion and climate change: impacts on UV radiation, Photochem. Photobio. S., 14, 19-52, doi:10.1039/c4pp90032d, 2015.

Castro, T., Mar, B., Longoria, R., Ruiz-Suárez, L. G., and Morales, L.: Surface albedo measurements in Mexico City metropolitan area, Atmósfera, 14, 69-74, available at: http://www.scielo.org.mx/scielo.php?script=sci_arttext\&pid= S0187-62362001000200002\&lng=es\&tlng=en (last access: 28 October 2016), 2001.

Cede, A., Herman, J., Richter, A., Krotkov, N., and Burrows, J.: Measurements of nitrogen dioxide total column amount using Brewer double spectrophotometer in direct Sun mode, J. Geophys. Res., 111, D05304, doi:10.1029/2005JD006584, 2006.

Chubarova, N. Y., Sviridenkov, M. A., Smirnov, A., and Holben, B. N.: Assessments of urban aerosol pollution in Moscow and its radiative effects, Atmos. Meas. Tech., 4, 367-378, doi:10.5194/amt-4-367-2011, 2011.

CIE: A reference action spectrum for ultraviolet induced erythema in human skin, edited by: MacKinley, A. F. and Diffey, B. L., CIE J., 6, 17-22, 1987. 
City of Warsaw: Ecophysiographic Study for Purposes of the Study of Conditions and Directions of Spatial Management, available at: http://architektura.um.warszawa.pl/ekofizjografia\# do_pobrania (last access: 28 October 2016), 2006 (in Polish).

Cleveland, W. S.: Robust Locally Weighted Regression and Smoothing Scatterplots, J. Am. Stat. Assoc., 74, 829-836, 1979.

Corr, C. A., Krotkov, N., Madronich, S., Slusser, J. R., Holben, B., Gao, W., Flynn, J., Lefer, B., and Kreidenweis, S. M.: Retrieval of aerosol single scattering albedo at ultraviolet wavelengths at the T1 site during MILAGRO, Atmos. Chem. Phys., 9, 58135827, doi:10.5194/acp-9-5813-2009, 2009.

Daniel, W. W. and Cross, C. L.: Biostatistics: a foundation for analysis in the health sciences, John Wiley and Sons, New York, USA, 2013.

De Bock, V., De Backer, H., Van Malderen, R., Mangold, A., and Delcloo, A.: Relations between erythemal UV dose, global solar radiation, total ozone column and aerosol optical depth at Uccle, Belgium, Atmos. Chem. Phys., 14, 12251-12270, doi:10.5194/acp-14-12251-2014, 2014.

Deng, X., Zhou, X., Tie, X., Wu D., Li, F., Tan, H., and Deng, T.: Attenuation of ultraviolet radiation reaching the surface due to atmospheric aerosols in Guangzhou, Chin. Sci. Bull., 57, 2759, doi:10.1007/s11434-012-5172-5, 2012.

Fioletov, V. E., Kerr, J. B., McElroy, C. T., Wardle, D. I., Savastiouk, V., and Grajnar, T. S.: The Brewer reference triad, Geophys. Res. Lett. 32, L20805, doi:10.1029/2005GL024244, 2005.

Fortuniak, K., Kłysik, K., and Wibig, J.: Urban-rural contrasts of meteorological parameters in Łódź, J. Theor. Appl. Climatol., 84, 91-101, doi:10.1007/s00704-005-0147-y, 2006.

Fountoulakis, I., Bais, A. F., Fragkos, K., Meleti, C., Tourpali, K., and Zempila, M. M.: Short- and long-term variability of spectral solar UV irradiance at Thessaloniki, Greece: effects of changes in aerosols, total ozone and clouds, Atmos. Chem. Phys., 16, 2493 2505, doi:10.5194/acp-16-2493-2016, 2016.

Greinert, R., de Vries, E., Erdmann, F., Espina, C., Auvinen, A., Kesminiene, A., and Schuz, J.: European Code against Cancer 4th edition: Ultraviolet radiation and cancer, Cancer Epidem. Biomar., 39, S75-S83, 2015.

Gröbner, J. and Schreder, J.: Protocol of the intercomparison at the Polish Geophysical Institute, Warsaw, Poland, 2022 May 2004 with the travelling standard spectroradiometer B5503 from ECUV within the project QASUME, available at: http://www.pmodwrc.ch/wcc_uv/qasume_audit/reports/ 2004_05_poland_warsaw_PGI1.pdf (last access: 28 October 2016), 2004.

Gröbner, J., Schreder, J., Kazadzis, S., Bais, A. F., Blumthaler, M., Görts, P., Tax, R., Koskela, T., Seckmeyer, G., Webb, A. R., and Rembges, D.: Traveling reference spectroradiometer for routine quality assurance of spectral solar ultraviolet irradiance measurements, Appl. Optics, 44, 5321-5331, 2005.

Gröbner, J., Blumthaler, M., Kazadzis, S., Bais, A. F., Webb, A. R., Schreder, J., and Rembges, D.: Quality assurance of spectral solar UV measurements: Results from 25 UV monitoring sites in Europe, 2002 to 2004, Metrologia, 43, S66-S71, doi:10.1088/0026-1394/43/2/S14, 2006.

Haberlie, A. M., Ashley, W. S., and Pingel, T. J.: The effect of urbanisation on the climatology of thunderstorm initiation, Q. J. Roy. Meteor. Soc., 144, 663-675, doi:10.1002/qj.2499, 2015.
Ichoku, C., Kaufman, Y. J., Remer, L. A., and Levy, R.: Global aerosol remote sensing from MODIS, Adv. Space Res., 34, 820 827, doi:10.1016/j.asr.2003.07.071, 2004.

Inoue, T. and Kimura, F.: Urban effects on low-level clouds around the Tokyo metropolitan area on clear summer days, Geophys. Res, Lett. 31, L05103, doi:10.1029/2003GL018908, 2004.

Jin, M., Shepherd, J. M., and King, M. D.: Urban aerosols and their variations with clouds and rainfall: A case study for New York and Houston, J. Geophys. Res., 110, D10S20, doi:10.1029/2004JD005081, 2005.

Kazadzis, S., Bais, A., Balis, D., Kouremeti, N., Zempila, M., Arola, A., Giannakaki, E., Amiridis, V., and Kazantzidis, A.: Spatial and temporal UV irradiance and aerosol variability within the area of an OMI satellite pixel, Atmos. Chem. Phys., 9, 4593-4601, doi:10.5194/acp-9-4593-2009, 2009a.

Kazadzis, S., Kouremeti, N., Bais, A., Kazantzidis, A., and Meleti, C.: Aerosol forcing efficiency in the UVA region from spectral solar irradiance measurements at an urban environment, Ann. Geophys., 27, 2515-2522, doi:10.5194/angeo-27-25152009, 2009b.

Krzyścin, J. W., Sobolewski, P., Jarosławski, J., Podgórski, J., and Rajewska-Więch, B.: Erythemal UV observation at Belsk, Poland, in the period 1976-2008: Data homogenization, climatology, and trends, Acta Geophys., 59, 155-182, doi:10.2478/s11600-010-0036-3, 2011.

Marionnet, C., Pierrard, C., Golebiewski, C., and Bernerd, F.: Diversity of Biological Effects Induced by Longwave UVA Rays (UVA1) in Reconstructed Skin, PLoS ONE, 9, e105263, doi:10.1371/journal.pone.0105263, 2014.

Mayer, B. and Kylling, A.: Technical note: The libRadtran software package for radiative transfer calculations - description and examples of use, Atmos. Chem. Phys., 5, 1855-1877, doi:10.5194/acp-5-1855-2005, 2005.

Miao S. G., Chen, F., Lemone, M. A., Tewari, M., Li, Q. C., and Wang, Y. C.: An observational and modeling study of characteristics of urban heat island and boundary structures in Beijing, $\mathrm{J}$. Appl. Meteorol. Clim., 48, 484-501, 2009.

NASA: AERONET data, available at: http://aeronet.gsfc.nasa.gov/, last access: 2 November 2016a.

NASA: MODIS data, available at: https://ladsweb.nascom.nasa. gov/search/, last access: 2 November 2016b.

Nikitidou, E., Kazantzidis, A., De Bock, V., and De Backer, H.: The aerosol forcing efficiency in the UV region and the estimation of single scattering albedo at typical West European site, Atmos. Environ., 69, 313-320, doi:10.1016/j.atmosenv.2012.12.035, 2013.

Papayannis, A., Balis, D., Bais, A., van der Bergh, H., Calpini, B., Durieux, E., Fiorani, L., Jaquet, L., Ziomas, I., and Zerefos, C. S.: Role of urban and suburban aerosols on solar UV radiation over Athens, Greece, Atmos. Environ., 32, 2193-2201, doi:10.1016/S1352-2310(97)00411-1, 1998.

Parisi, A. V., Sabburg, J., Kimlin, M. G., and Downs, N.: Measured and modeled contributions to UV exposures by the albedo of surfaces in an urban environment, Theor. Appl. Climatol., 76, 181188, 2003.

Pietruczuk, A.: Short term variability of aerosol optical thickness at Belsk for the period 2002-2010, Atmos. Environ., 79, 744-750, doi:10.1016/j.atmosenv.2013.07.054, 2013. 
Polish Ministry of Environment: Decree of the Minister of Environment on Levels of Selected Substances in the Atmosphere, 24 August 2014 (Dz.U. 2012 poz. 1031), available at: http:// isap.sejm.gov.pl/DetailsServlet?id=WDU20120001031 (last access: 28 October 2016), 2014 (in Polish).

Romanov P.: Urban influence on cloud cover estimates from satellite data, Atmos. Environ, 33, 4163-4172, 1999.

Sabziparvar, A. A., Shine, K. P., and Forster, P. M.: A modelderived global climatology of UV irradiation at the Earth's surface, Photochem. Photobiol., 69, 193-202, doi:10.1111/j.17511097.1999.tb03273.x, 1999.

Shepherd, J. M.: A review of current investigations of urbaninduced rainfall and recommendations for the future, Earth Interact., 9, 1-27, doi:10.1175/EI156.1, 2005.

Slaper, H., Reinen, H. A., Blumthaler, M., Hube, M., and Kuik, F.: Comparing ground level spectrally resolved UV measurements from various instruments: A technique resolving effects of wavelength shifts and slit width, Geophys. Res. Lett., 22, 2721-2724, 1995.
Twomey, S.: The influence of pollution on the shortwave albedo of clouds, J. Atmos. Sci., 34, 1149-1152, 1977.

Zawadzka, O., Markowicz, K. M., Pietruczuk, A., Zielinski, T., and Jaroslawski, J.: Impact of urban pollution emitted in Warsaw on aerosol properties, Atmos. Environ., 69, 15-28, doi:10.1016/j.atmosenv.2012.11.065, 2013.

Zerefos, C. S., Tourpali, K., Eleftheratos, K., Kazadzis, S., Meleti, C., Feister, U., Koskela, T., and Heikkilä, A.: Evidence of a possible turning point in solar UV-B over Canada, Europe and Japan, Atmos. Chem. Phys., 12, 2469-2477, doi:10.5194/acp-12-24692012, 2012. 